\title{
REVIEW
}

\section{Total quality management of community health service}

\begin{abstract}
Shuliang Zhao ${ }^{1^{*}} \quad$ Xianjie $\mathrm{Jia}^{2}$
Abstract: At present, the community health service agencies need to build up total quality management (TQM) system. TQM is critical for community health service agencies to achieve sustainable development. Through measures such as perfecting the monitoring mode, strengthening the support of labor resources and building a comprehensive quality management system, the community health service agencies can boost staff members enthusiasm and initiative, promote the further change of quality concept and improve their services. This paper reviews the implementation of total quality management in community health service agencies and related issues.
\end{abstract}

Keywords: Community health services; Total quality management; Service agencies

In recent years, Community health services in China have developed rapidly. Although community health services are growing rapidly in quantity, the quality management has yet to be further improved. To explore how to help the Community Health Service agencies to improve the quality of service and to provide a reference for the service work.

\section{Community health service management status and problems}

\section{(1) The development of community health services.}

At present, part of the regional base were in line with the standard from the Ministry of Health about the community health service center as a street to set, and the service population are 30,000 to $50,000 .^{[1]}$ Due to the nearest convenience, low cost, good service attitude, Community Health services are well received by the masses.

Currently, there are some community health service agencies try to implement total quality management in China. For example, the inspection model of "six reunification" has been implemented in Xuanwu District, Nanjing city, Namely: unified inspection standards, unified inspection methods, unified inspection time, unified

\footnotetext{
Received: July 11, 2017;Accepted: September 5, 2017; Published: October 20, 2017

* Correspondence to: Shuliang Zhao, School of Social Development and Public Policy, Beijing Normal University, Beijing 100875, China; Email: 187365776@qq.com

2 Department of Epidemiology, Bengbu Medical College, Bengbu 233000, Anhui, China

Citation: Zhao S, Jia X. Total quality management of community health service. Adv Gen Pract Med, 2017, 1(1): 1-4

Copyright: (c) 2017 Shuliang Zhao et al.This is an open access article distributed under the terms of the Creative Commons Attribution License, which permits unrestricted use, distribution, and reproduction in any medium, provided the original author and source are credited.
}

inspection of the contents of a unified inspection personnel, unified inspection purposes. The standard used was argument, and effectively meet the region special point of the integrated program, absorbing successful experience of total quality management from other areas, the content is divided into five areas: chronic disease management quality medical quality, medical technology pharmacy quality, nursing and nosocomial infection management quality and community health service management quality. By positive, the ability of total quality management improved, while the quality of the relevant staff improved also. The enthusiasm and initiative promote, the concept of quality changed, and achieved good results.

At present, although the management work of the community health service has been a certain development, there are still many problems, especially in community health services quality management are still obviously inadequate.

(2) The problem of quality management in community health service agencies.

There are still weak points about community health service quality management work due to service facilities, medical facilities equipment, technical strength and other aspects of the restrictions, combined with health insurance and other policies system is not perfect, the quality of community health services to be a further level step up. With the liberalization of medical insurance policy, slow disease management release, collective access to individual medical institutions, drug prices, community Health service agencies, especially private institutions to 
survive the pressure increased year by year. Due to survival pressure and profitability, community health service agencies public welfare Service has not been fully reflected.

Community health service agencies in the human resources (HR) management mechanism need to be improved. The current community health professionals are mostly from the 'grass-roots' health members who are lack of the ability to meet the health services need and they can not adapt to the "six in one" comprehensive medical health service work needs. ${ }^{[2]}$ Due to the human resource of community health service limits, coupled with a higher intensity of work, resulting in the number of staff is not enough and instability, then affecting the quality of service and level. In recent years, HR training have been on carried out in Shanghai city and areas where the community health services are better and achieved some performances. But the HR management mechanism of health service organization still needs further improve in whole country, especially in areas where medical and health resources are not sufficient.

Quality management evaluation work still need to improve. The current medical quality management model and quality evaluation system can not accurately reflect the difference between the health service centres, so the difference among the ratings of the hospital is not significant. The assessment and evaluation system need to be further improved and optimized and can reflect the quality of community health service accurately, objectively, impartially and comprehensively.

The task of community health service quality management is arduous. The quality management from the change of service places and objects and the updates of service contents and methods will bring new challenges. The Community Health Service work need to be further improved, although some exploration have been done, but are still limited, superficial and the recycling management operation mechanism is not perfect. Compared with the hospital, the quality management for community health service is more complex, heterogeneity and particularity because of the variety of disciplines, operational diversity, decent service, personnel technology, imbalance of capacity of quality control.

\section{The significance of total quality manage- ment}

In recent years, China's community health service agencies are experiencing a rapid changing. The government has developed and implemented a series of new policy and community health service work norms to deepen the reform of urban medicine health system, op- timize the structure of urban health resources, the development of community health services, and strive to meet the basic needs of the masses of health services. In this process, total quality management is applied in community health services which brought a new quality management ideas to the community health service agencies and made the quality of community health services overall improved through the establishment of scientific and efficient quality management system.

Community Health Services is a special commodity, its quality of services includes the formation of quality of service and the quality of work. With the market economy continuous improvement and further deepening of health system reform, community health Service will gradually be pushed to the market. Only to improve the overall quality of service, the level of management and service, community health services can get faster development. ${ }^{[3]}$

The ultimate goal of quality management of community health services is to meet the needs of different levels of community health services. The purpose of quality management applied to community health services is to promote the community health services to build an effective and satisfying service environment of "patientcentred security" to improve the efficiency and quality. Therefore, the implementation of total quality management can not only improve the quality of product and service, but also have a profound impact at the level of transformation and reorganization of community health services.

\section{The main content of total quality manage- ment}

Total Quality Management was named by Fergenberg, the famous American expert in the 1960s. ${ }^{[4]}$ It has now become a highly systematic science based on the tradition quality management with the development of science and technology.

Total Quality Management is a management methods centred by quality, based on full participation and the core is the customer's satisfaction and all members' benefits. ${ }^{[5]}$

The basic characteristics of Total Quality Management include the followings: (1) Comprehensive: all work of different departments comply with quality management. (2) All: all members must participate in learning, training. (3) Whole: from the beginning of the event to the end, all aspects of the entire process comply with quality management.

The basic working method of Total Quality Management is the Deming PDCA cycle work law, also known 
as 'Deming ring' including four steps: (1) Planning stage: to find out the question of the quality, the cause of the quality problem, and the solutions. (2) Implementation phase: the solution policy seriously put into practice. (3) Checking stage: to investigate and analyse the effect of the implementation. (4) Processing stage: to summarize the successful experience, and put the problem into the next cycle.

\section{Model exploration of Total Quality Man- agement}

To implement a comprehensive quality management, community health service agencies should pass through all the staff and departments work together to establish a quality system during the whole process of community health services institutional activities, to ensure that "prevention first" work policy implementation, better "for the people's health services for the economy construction services. "As a system engineering, the requirements of 'Three Comprehensives, One Diverse", that is, a comprehensive quality management, the whole process of quality management, full participate in quality management and scientific, diverse methods. ${ }^{[6]}$

To ensure and improve community health service quality system, all the work of the community health service should work move to form an effective unit and to carry out a comprehensive quality management from financing to human resources management, system construction, and so on.

The whole process of quality management should insist on the idea of prevention first, innovation and serving the customer.

To educate and train the whole staff; to develop personnel quality responsibility system for all departments, to carry out the responsibility, right and benefit, and to organize various quality management activities.

Adopt a variety of methods for quality management, such as to urge, evaluate, investigate the quality of community health services, and analysis and solve quality problems as well as to improve the evaluation system, to strengthen the quality of community health service management and the safety education, to enhance the sense of safety, and to improve the the quality and ability to consciously participate in quality management.

\section{Several issues about community health ser- vices}

After the establishment of the health service organization management policy, it is very important to implement completely, to understand, be familiar with the policy, and to integrate of the policy into every link of quality management, meanwhile to implement and adhere to quality training and quality management training, to establish a "full participation" of the concept of Total Quality Management. ${ }^{[7]}$

To establish and implement a standardized rational medication. To carry out the basic drug system pilot in the community, community health service agencies, the required drugs are from the government centralized procurement, unified distribution, to ensure that its price is lower than the average price in market. At the same time, explore the establishment of a zero-rate sales system for community health services, which can be sold to the community with a zero-percent rate of sales, and the difference will be compensated by the government.

To perfect the matching talent system, and build the quality of the talent team. To actively guide the high quality talents of urban health surplus personnel to transfer to community health service agencies. ${ }^{[8]}$ To encourage senior health professionals to work part-time in the community. The whole staff in community health service shall be hired on contract, and the performance salary is the main income of employees through the number of services, quality of service, residents satisfaction and other indicators for performance verification, to encourage medical staff focus on community health management, prevention of health care and rehabilitation. To establish a relatively complete, mature, in line with market demand for health service personnel training system in all medical schools.

To strengthen the management of common and frequent disease. The appropriate community health technology should be vigorously promoted, to carry out comprehensive control and standardize the management of single disease such as high blood pressure, diabetes, and so on. For common diseases, frequent disease, the main work is to prevent, prevention and treatment combined, reasonable inspection, reasonable drug use, active service, to facilitate the patients, standard referral, and control the medical expenses. ${ }^{[9]}$ In addition, community health services should strengthen the basic medical insurance, medical aid connection, guide the insured people make full use of community health services, to make a diagnosis and give treatment in community for those with common diseases, frequently disease and chronic diseases.

\section{References}

[1] Ministry of Health and the State Administration of Traditional Chinese Medicine. Urban Community Health Service Management Office Law (Trial) , 2006

[2] Dong YN, Liu LH, Liu BS, et al. Exploration of Community 
Health Service Quality Management. Chinese J Pract Med, 2012, 3: 282-284

[3] Liu C, Zhou L. Community health service institutions to implement the concept of brand strategy. Med And Philos , 2014, 28: 7-9

[4] Fergenberg. Total Quality Management. 1991, 25-26

[5] Yu T, Shi PW and Zhu H. Health and disease prevention institutions to implement a comprehensive quality management work. Chinese J Public Health Care, 1999, 15: $226-227$

[6] Yu Z, Zhang L. Total Quality Management and its application in hospital management. $J$ Hosp Adm, 2006, 22: $467-470$
[7] Wang YQ, Xu M, Mou WY,et al.On the comprehensive quality management of the hospital and the real. Chinese Health Qual Manage, 2004, 11: 21-22

[8] Wang CY. Implementation of Total Quality Management, improve the level of hospital services. Health Dig ,2006, 3 : $48-51$

[9] Chen Q. Community health service center medical quality management status and countermeasures. Chinese Gen Pract ,2006, 8: 1003 